\title{
EFFECTS OF ELECTROPLATED ZINC-NICKEL ALLOY COATINGS ON THE FATIGUE STRENGTH OF AISI 4340 HIGH STRENGTH STEEL
}

\author{
H. J. C. Voorwald, I.M. Miguel and M.Y.P. Costa \\ Department of Materials and Technology, State University of São Paulo, Cep. 12516-410, BRAZIL.
}

\begin{abstract}
It is well known that fatigue behaviour is an important parameter to be considered in mechanical components subjected to constant and variable amplitude loadings. In combination with corrosion phenomenon, fatigue effects were responsible for proximally $64 \%$ of fails that occur in metallic parts of aeronautical accidents in the last 30 years. Recovered substrates have been extensively used in the aerospace field. Cadmium electroplating has been widely applied to promote protective coatings in aeronautical components, resulting in excellent corrosion protection combined with a good performance in cyclic loading. Ecological considerations allied to the increasing demands for corrosion resistance, resulted in the search for possible alternatives. Zinc-nickel alloys received considerable interest recently, since these coatings showed some advantages such as a good resistance to white and red rust, high plating rates and acceptation in the market. In this study the effects of zinc-nickel coatings electroplated on AISI 4340 high strength steel were analysed on rotating bending and axial fatigue strength, corrosion and adhesion resistance. Compressive residual stress field was measured by a X-ray tensometry prior to fatigue tests. Optical microscopy images showed coating thicknesses, adhesion and the existence of an uniform coverage of nearly all substrates. The fractured fatigue specimens were investigated using a scanning electron microscope. Three different zinc-nickel coating thicknesses were tested and comparison with rotating bending fatigue data from specimens cadmium electroplated and heat treated at $190^{\circ} \mathrm{C}$ for 3,8 and 24 hours to avoid the diffusion of hydrogen in the substrate, was performed. Experimental results showed effect of coatings on the AISI 4340 steel behaviour when submitted to fatigue testing and the existence of coating thickness influence on the fatigue strength.
\end{abstract}

\section{INTRODUCTION}

In recent years, with higher worldwide demand for improved quality and corrosion resistance, alternative coatings are required. Zinc alloys, particularly zinc-nickel, have been extensively studied due to their technological application in protection against corrosion, as an alternative to cadmium alloys [1-3]. These coatings are widely applied in automotive industry, normally with thicknesses of $10 \mu \mathrm{m}$ [4]. These alloys have also been considered for several applications such as in electrocatalytic water electrolysis [5], as coatings for steel cord reinforcement of tires [6] and in the electronics industry [7]. In the Brazilian aeronautical industry, despite of the excellent properties as agent protective showed by $\mathrm{Zn}-\mathrm{Ni}$ coatings, these alloys are still in study and in a development stage. In this industrial segment, a good resistance to fatigue is required, which result in another difficulty in the search of alternatives to cadmium as coatings in high strength steel.

In case of aeronautical applications, protection against corrosion must be combined with fatigue resistance.

The aim of this study was to analyze the effects on AISI 4340 steel, in the rotating bending fatigue behavior, of zinc-nickel coating thickness electroplated on AISI 4340 steel and to compare with the results obtained by cadmium electroplating. Fracture planes of the fatigue specimens were examined using a scanning electron microscopy in order to identify the crack initiation points. Optical metallographic was used to investigate the existence of an uniform coverage of nearly all substrates. 
Studies of the resistance against corrosion were carried out using salt spray tests and the results showed according to ASTM B117. The residual stresses promoted by machining and the electroplating process were obtained and compared with base material.

Residual stresses were determined by X-ray diffraction method, using the Ray stress equipment, whose characteristics are described in [8]. The accuracy of stress measurements was $\Delta \sigma= \pm 20 \mathrm{MPa}$. In order to obtain the stress distribution by depth, the layers of specimens were removed by electrolytic polishing with a non-acid solution.

\section{EXPERIMENTAL PROCEDURE}

The base material used in this work was the AISI 4340 steel widely applied in aircraft components where strength and toughness are fundamental design requirements. The chemical composition of the steel is in accordance to required standards.

Rotating bending fatigue test specimens were machined from hot rolled quenched and tempered bars. Fatigue tests specimens were quenched from $(815-845){ }^{\circ} \mathrm{C}$ in oil $\left(20^{\circ} \mathrm{C}\right)$ and tempered in the range $(520 \pm 5){ }^{\circ} \mathrm{C}$ for two hours. Mechanical properties of the steel after the treatment are: hardness $=(38-42) \mathrm{HRc}$, yield strength $=1118 \mathrm{MPa}$ and ultimate tensile strength $=1210 \mathrm{MPa}$. After final preparation, specimens were subjected to stress relieve heat treatment at $190{ }^{\circ} \mathrm{C}$ for four hours with posterior cooling in still air, to reduce residual stresses induced by machining.

Specimens were machined according to specifications, polished with 600 grit papers, inspected dimensionally and by magnetic particle inspection. Average superficial roughness in the reduced section of the specimens was $\mathrm{R}_{\mathrm{a}} \approx 2.75 \mu \mathrm{m}$ with standard deviation equal to $0,89 \mu \mathrm{m}$.

\subsection{CADMIUM AND ZINC-NICKEL ALLOYS ELECTROPLATING.}

The cadmium electroplating was carried out by rotative drum process, during 1 minute to 10 minutes to produce coating thicknesses in the range $8 \mu \mathrm{m}$ to $13 \mu \mathrm{m}$. Parameters employed in this process were: cadmium salt solution $20-30$ [g/l], sodium cyanide solution 90 - 200 [g/L], sodium hydroxide solution $10-20[\mathrm{~g} / \mathrm{L}]$, relations $\mathrm{Cn} / \mathrm{Cd}$ equal 4:1 - 6:1, temperature room, continuous current between $1-5\left[\mathrm{~A} / \mathrm{dm}^{2}\right]$, voltage anode/cathode $1-4$ [volts] and electrodeposition velocity between $0,2-1,5[\mu \mathrm{m} / \mathrm{min}]$. Once finished the bath deposition, specimens were treated with sodium cyanide solution for 15 seconds to 30 seconds, treated with stream water and dried with hot air for 2 minutes to 4 minutes. The last step in the cadmium electrodeposition process was dehydrogenation by heat treatment to avoid the diffusion of hydrogen in the substrate.

The zinc-nickel electroplating was carried out in accordance to the plating control parameters shown in table 1. Prior to the deposition, pieces were submitted to the following sequence of pretreatment: alkaline clean, acid pickling and rinsing with distilled water. After plating, specimens were subjected to rinsing and drying and submitted to hydrogen embrittlement relief treatment at $190^{\circ} \mathrm{C}$ for 24 hours.

\subsection{Rotating BENDing FATIGUE TESTS}

Rotating bending fatigue tests were performed using a sinusoidal loading at frequency of $50 \mathrm{~Hz}$ with stress ratio $\mathrm{R}$ equal to $-1,0$ in air and at room temperature. These tests consider as fatigue strength complete fracture of the specimens or $10^{7}$ load cycles. Nine groups of fatigue specimens were prepared to obtain S-N curves for rotating bending fatigue tests.

\subsection{RESIDUAL STRESS ANALYSIS}

The residual stress analysis were conduced by portable X-ray apparatus with an air cooled doubleanode X-ray tube, provided with a stress measurement unit and focusing camera for phase analysis. The characteristics of the equipment used in this analysis were showed by Monin et al 
[9] and the methodology applied during the tests is described. Specimens used in these tests have the same specification adopted in the fatigue tests. Measurements were carried out with base material and base material zinc-nickel alloy electroplated, at the interface substrate/coatings and inside substrate.

\subsection{FRACTURE SURFACE ANALYSIS AND METALLOGRAPHIC CHARACTERIZATION.}

Fracture surface analysis was carried out on rotating bending fatigue test specimens by scanning electron microscope, model Leo $435 \mathrm{Vpi}$. The metallographic analysis was carried out by optical microscope model Neophot 21.

Images were used to identify the existence or not of an uniform coverage of nearly all substrates and to investigate the better performance of the coatings with respect to their adherence properties. Thicknesses of the coatings were measured and compared in order to verify their relationship with fatigue behavior. The metallographic analysis was carried out on specimens sectioned in the transversal orientation, inlaid work in acrylic resin, prepared using 80 at 1000 graduate waterproof papers and polished with 99,98\% Alumina suspension.

\subsection{RESULTS AND DISCUSSION}

\subsubsection{FATIGUE TESTS}

Figure 1 shows $\mathrm{SxN}$ curves for rotating bending fatigue tests for the base material, hard chromium electroplating, cadmium electroplating and zinc-nickel electroplating.

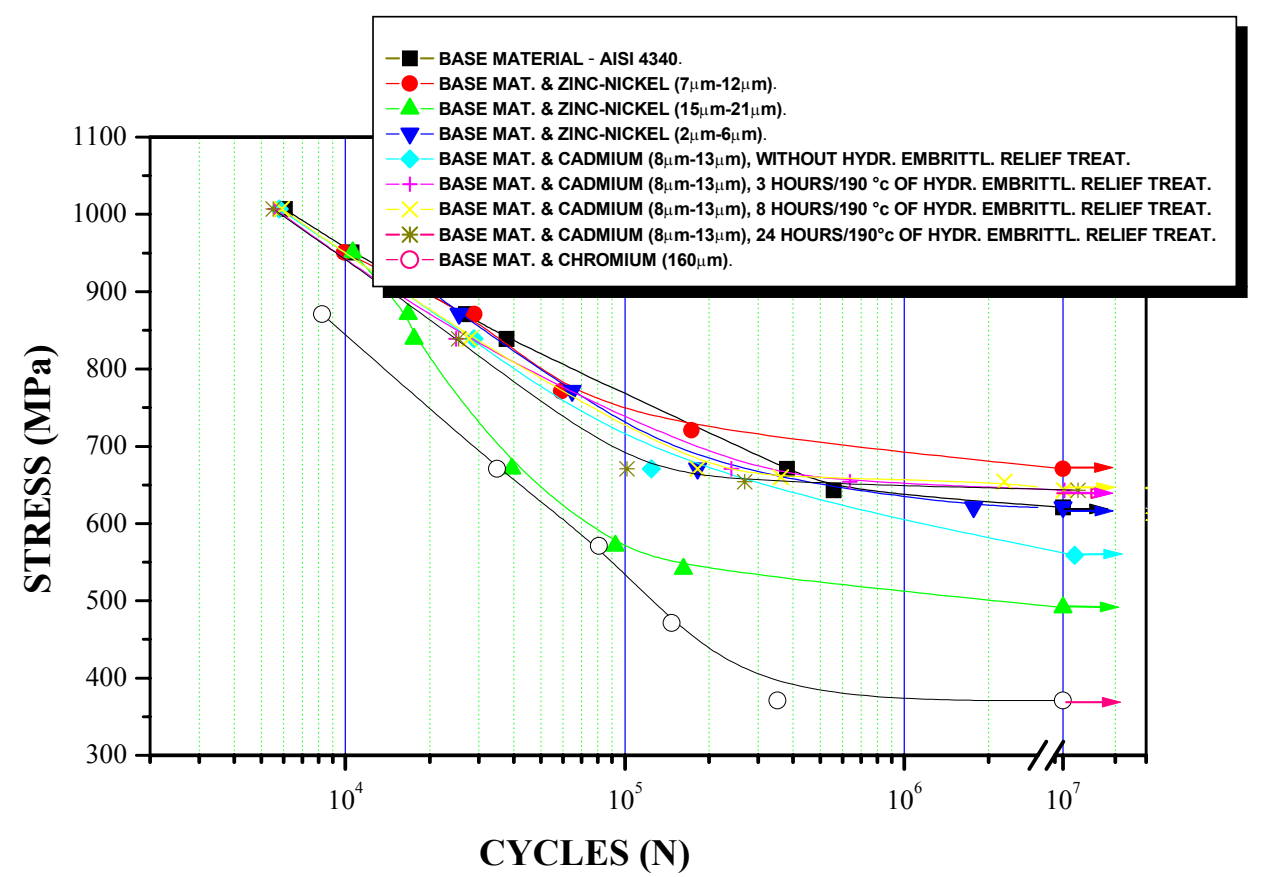

Figure 1: Rotating Bending fatigue test. Based material, zinck-nickel alloys, cadmium and chromium electroplated specimen.

Experimental data for base material in figure 1 will be used in this work as a reference to be 
compared with the fatigue strength of AISI 4340 steel electroplated with cadmium and zinc-nickel alloys. It is possible to observe from figure 1 the significant reduction in the fatigue life of specimens chromium electroplated.

The SxN curve for the specimens tested after cadmium electroplating, without post heat treatment shows decrease in fatigue strength in comparison to the base material, for low and high cycles.

To understand the effect of zinc-nickel electroplated coating on the SxN curves of AISI 4340 steel, figure 2 should be considered. From figure 2, which indicates residual stress at interface substrate-coating and inside base metal it is possible to observe that compressive residual stresses at interface decreases with the decrease in the coating thickness. Maximum compressive residual stress at interface is obtained for base metal. Interesting is to observe the variation of residual stress increasing the distance from the interface. After $0.1 \mathrm{~mm}$, specimens zinc-nickel electroplated coated with thicknesses in the range of $7 \mu \mathrm{m}-12 \mu \mathrm{m}$ and $15 \mu \mathrm{m}-21 \mu \mathrm{m}$, showed tensile residual stresses of $20 \mathrm{MPa}$ and $60 \mathrm{MPa}$, respectively. For base material and zinc-nickel electroplated coating in the range of $2 \mu \mathrm{m}-6 \mu \mathrm{m}$, table 1 shows that at $0.1 \mathrm{~mm}$ from the interface residual stresses are $-260 \mathrm{MPa}$ and $20 \mathrm{MPa}$, respectively.

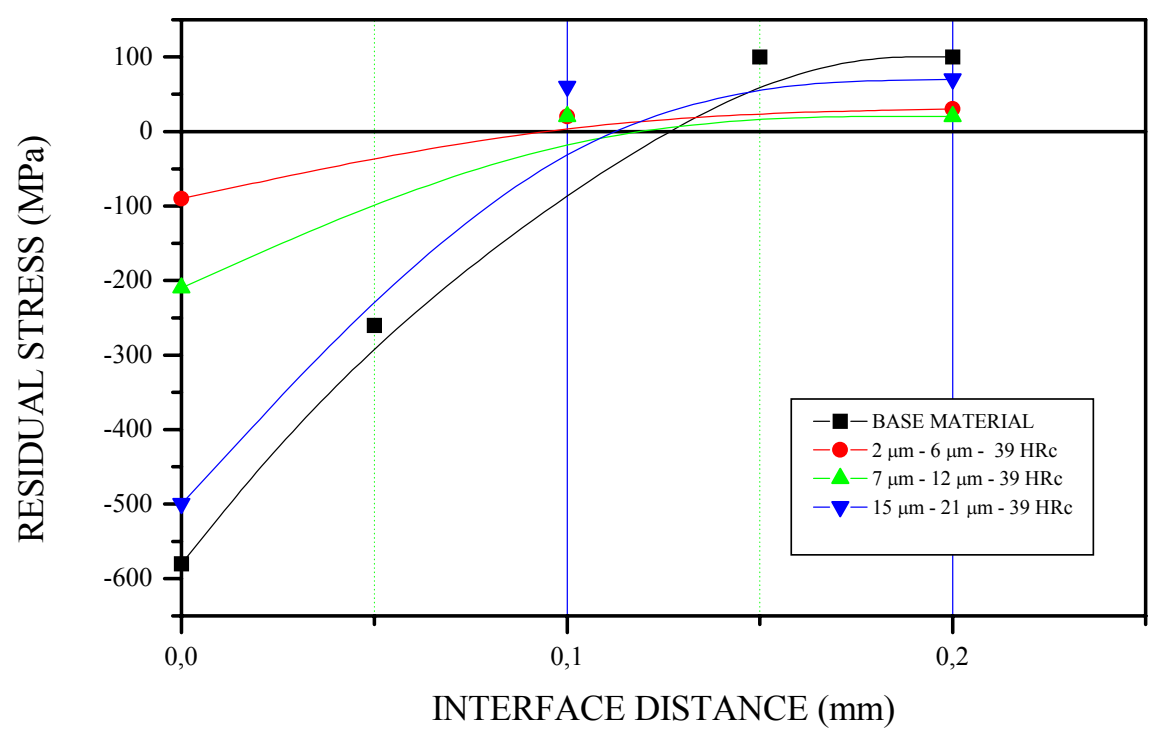

Figure 2: Residual stress measurements tests.

At $0.2 \mathrm{~mm}$ from the interface, all conditions show tensile residual stresses, in the range $20 \mathrm{MPa}$ to $100 \mathrm{MPa}$. It is interesting to observe for zinc-nickel electroplated coating $15 \mu \mathrm{m}-21 \mu \mathrm{m}$, the variation in the residual stresses from $500 \mathrm{MPa}$ compressive at interface to $60 \mathrm{MPa}$ tensile at 0.1 $\mathrm{mm}$ from this point. Comparison between residual stresses at $0.1 \mathrm{~mm}$ and $0.2 \mathrm{~mm}$ from the interface indicate, exception made for the base metal, almost the same results, for zinc-nickel electroplated coatings.

It is well known that delay in fatigue crack nucleation and propagation results from the presence of compressive residual stress field which, consequently, increase fatigue strength. Compressive residual stress at interface for thicknesses $2 \mu \mathrm{m}-6 \mu \mathrm{m}, 7 \mu \mathrm{m}-12 \mu \mathrm{m}$ and $15 \mu \mathrm{m}-21$ $\mu \mathrm{m}$ were $90 \mathrm{MPa}, 210 \mathrm{MPa}$ and $500 \mathrm{MPa}$, respectively. To understand the behavior of the $\mathrm{SxN}$ 
curves represented in figure 3, residual stresses at $0.1 \mathrm{~mm}$ from the interface coating-substrate must be considered. The highest residual stresses was obtained for zinc-nickel electroplated coating with thickness $15 \mu \mathrm{m}-21 \mu \mathrm{m}$, in comparison to $2 \mu \mathrm{m}-6 \mu \mathrm{m}$ and $7 \mu \mathrm{m}-12 \mu \mathrm{m}$.

Figure 2 indicates residual stresses behavior with compressive values at interface and tensile at $0,1 \mathrm{~mm}$ from that point, for base material and the three zinc-nickel electroplated coating thicknesses studied.

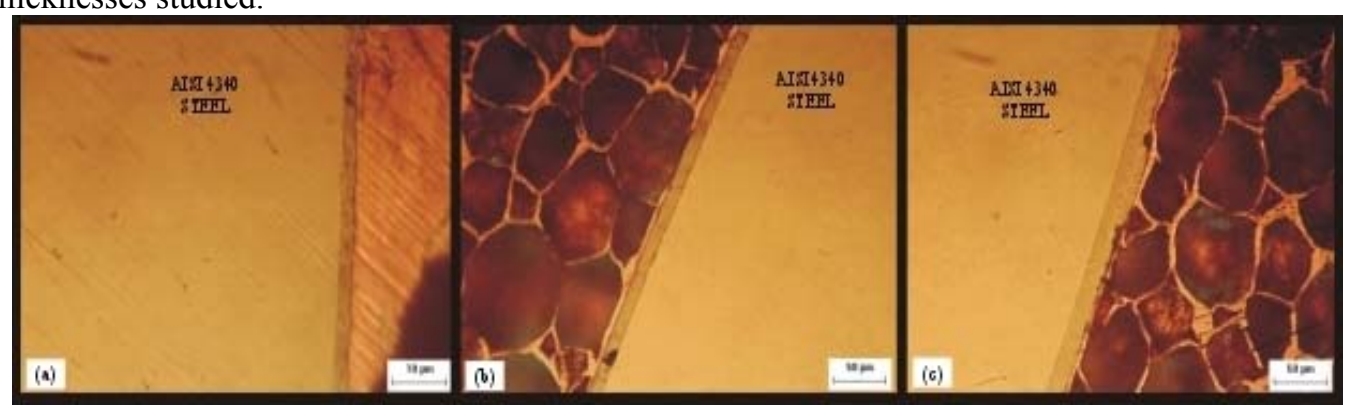

Figure 3: Optical microscopy. Thicknesses and homogeneity of zinc-nickel layers: (a) $=2 \mu \mathrm{m}-$ $6 \mu \mathrm{m},(\mathrm{b})=7 \mu \mathrm{m}-12 \mu \mathrm{m}$ and (c) $=15 \mu \mathrm{m}-21 \mu \mathrm{m}$.

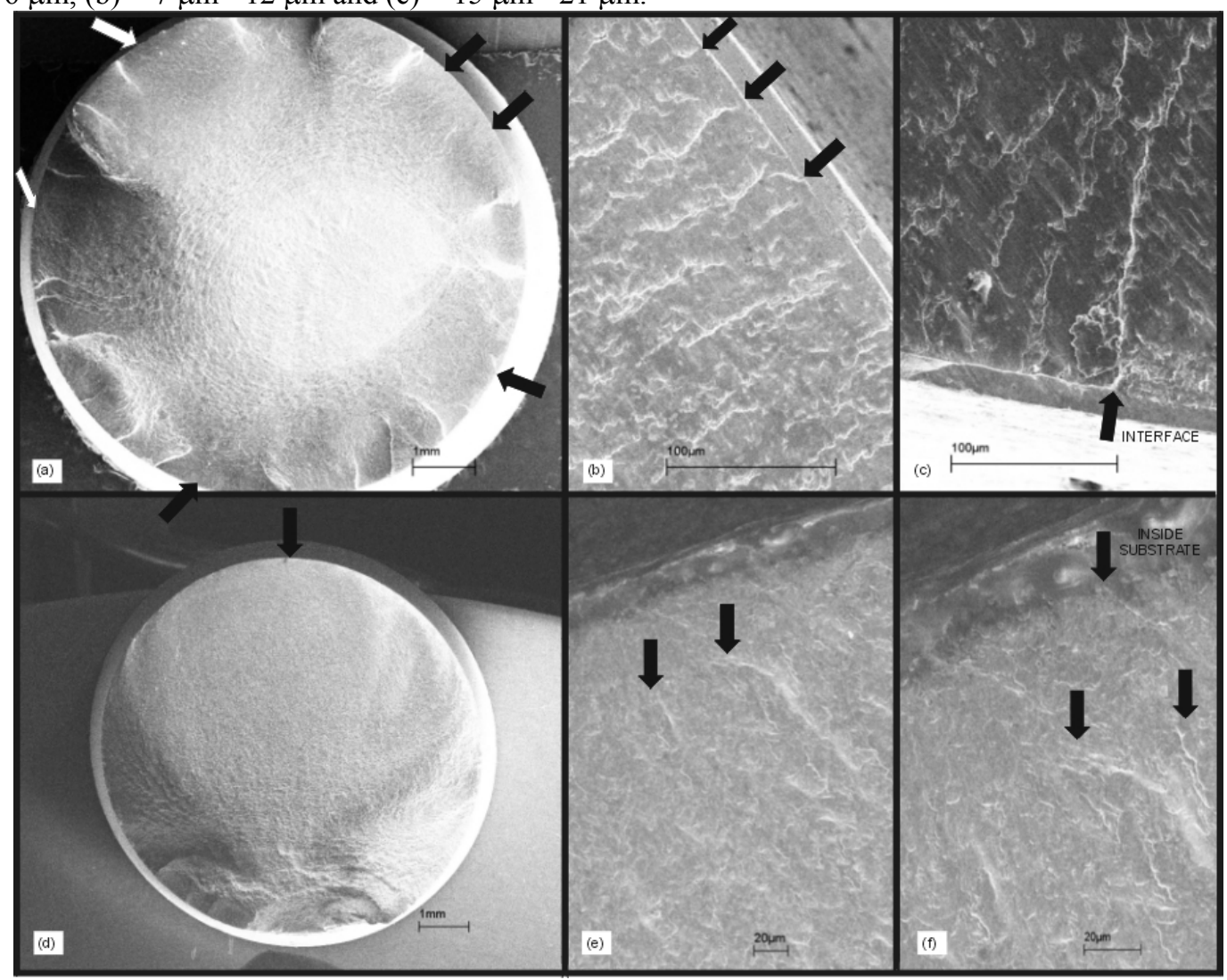

Figure 4: Scanning electronic microscopy. AISI 4340 zinc-nickel alloy coatings. Thicknesses between $15 \mu \mathrm{m}-21 \mu \mathrm{m}$.

Figure 3 (a) shows an optical microscopy image of zinc-nickel electroplated coating, $2 \mu \mathrm{m}-6$ $\mu \mathrm{m}$ thick, with $1000 \mathrm{X}$ magnification. It is possible to verify that the coating layer is uniform and 
there are no signs of detachment of coating from the substrate. Figures 3 (b) and 3 (c) represent images from coating thicknesses $7 \mu \mathrm{m}-12 \mu \mathrm{m}$ and $15 \mu \mathrm{m}-21 \mu \mathrm{m}$. Coating homogeneity and strong adhesion with substrate are observed.

Figures 4 (a), (b) and (c) show represent fracture surfaces a rotating bending fatigue specimen tested at $951 \mathrm{MPa}$, fractured after 10600 cycles. Electroplated zinc-nickel coating thickness was in the range $15 \mu \mathrm{m}-21 \mu \mathrm{m}$. Figure 4 (a) represent the general fracture surface aspect with several crack origin sites around specimen surface. Figure 4 (b), indicates fatigue crack nucleation at interface coating-substrate. In figure 4 (c), fatigue crack nucleation at interface and propagation inside substrate, is shown. Figures 4 (d), (e) and (f) are associated to a fatigue specimen tested at $571 \mathrm{MPa}$, with a number of cycles to fracture equal to $\mathrm{N}=83600$.

Figures 4 (e) and (f) indicate fatigue crack nucleation inside substrate, associated to the variation in residual stresses from $500 \mathrm{MPa}$ compressive at interface to $600 \mathrm{MPa}$ tensile at $0.1 \mathrm{~mm}$ from this region.

2.6 CONCLUSIONS

1. For low cycle fatigue, differences in fatigue strength specimens exposed to $190{ }^{\circ} \mathrm{C}$ for 2,8 and24 hours were not observed. In high cycle fatigue some influence was detected, indicating better results for lower treatment times.

2. Reduction in the AISI 4340 steel rotating bending fatigue strength resulted from zinc-nickel electroplated coating in the thickness interval $15 \mu \mathrm{m}-21 \mu \mathrm{m}$. In the case $7 \mu \mathrm{m}-12 \mu \mathrm{m}$, experimental data indicate almost the same behavior, with respect to the fatigue strength, showed by AISI 4340 steel cadmium electroplated, $8 \mu \mathrm{m}-13 \mu \mathrm{m}$.

\section{REFERENCES}

1. I. M. Miguel, C. E. A. Silva, M. P. Peres, H. J. C. Voorwald. Study of influence of zinc-nickel and cadmium electroplated coatings on fatigue strength of aeronautical steels. FATIGUE, 2002, p. $15-23$.

2. S. B. Silva, L. H. Mascaro, S. A. S. Machado and L. A. Avaca Análise da composição de ligas de Zn-Ni depositadas sobre diferentes materiais. EBRATS 94. (1994) p. 15-23.

3. G. F. Hsu, Zinc-nickel alloy plating: An alternative to cadmium. Plating and Surface Finishing. 71,4 (1984) p. 52-55.

4. A. M. Alfantazi and U. Erb. Corrosion properties of pulse-plated zinc-nickel alloy coatings. Corrosion Engineering. (1996) pp. 880-888.

5. M. J. Giz; S. A. Machado, L. A. Avaca and E. R. Gonzalez. High area Ni-Zn and Ni-Co codeposits as hydrogen electrodes in alkaline solutions. Journal of Applied Electrochemistry, 22 (1992) p. 973-977.

6. J. Giridhar, W. J. Ooij, Surface Coating and Technology. 53 (1992) 35.

7. R. G. Baker and C. A. Holden. Zinc-nickel alloy electrodeposits: Rack plating. Plating and Surface Finishing, 72, 3 (1985) p. 54-57.

8.T. Gurova. Study of the residual stress state during plastic deformation under uniaxial tension in a 5,0 Cr and 0,5 Mo steel. Science Material. 36(9) (1997) p. 1031-1035.

9.V. Monin, J. R. Teodosio, and T.Gurova. A Portable X-ray apparatus for both stress measurement and phase analysis under field conditions. Advances in X-ray Analysis. 43 (2000) p. 66-71.

\subsection{ACKNOWLEDGEMENTS}

The authors are grateful for the support of this research by CAPES, ELEB/EMBRAER and FAENQUIL/DEMAR. 